These studies were supported by project grants from the Arthritis and Rheumatism Council of Great Britain, the Wellcome Foundation, and the Medical Research Council. The manuscript was typed by Miss Katy Cuninghame.

1 Cooper C. The epidemiology of osteoarthritis. In: Klippel J, Dieppe P, eds. Rheumatology. New York: CV Mosby, 1994:7.3.1-4.

2 Spector TD, Cooper C. Radiographic assessment of osteoarthritis: whither Kellgren and Lawrence? Osteoarthritis Cartilage 1993;1:203-6.

3 Felson DT. Epidemiology of hip and knee osteoarthritis. Epidemiol Rev 1988;10:1-28.

4 Croft P, Coggon D, Cruddas M, Cooper C. Osteoarthritis of the hip: an occupational disease in farmers. $B M F$ 1992;304:1269-72.

5 Tepper, S. Hochberg MC. Factors associated with hip osteoarthritis: data from the First National Health and Nutrition Examination Survey (NHANES-1). Am $\mathcal{f}$ Epidemiol 1993;137:1081-8.

6 Van Saase JLCM. Osteoarthrosis in the general population: a follow-up study of osteoarthrosis of the hip. Rotterdam: Erasmus University, 1989 (dissertation)

7 Lequesne M, Azorin M, Lamotte J. Post-traumatic osteoarthritis of the hip. Rev Rhum 1993;60:698-704.

8 Croft P, Cooper C, Wickham C, Coggon D. Osteoarthritis of the hip and acetabular dysplasia. Ann Rheum Dis 1991; 50:308-10.

9 Egger P, Cooper C, Hart D, Doyle D, Coggon D, Spector T. Patterns of joint involvement in osteoarthritis of the hand: the Chingford Study. $\mathcal{F}$ Rheumatol 1995;22:1509- 13.
10 Croft P. Cooper C, Wickham C, Coggon D. Is the hip involved in generalised osteoarthritis? $\mathrm{Br} \mathcal{F}$ Rheumatol 1992;31:325-8.

11 Cooper C, McAlindon T, Coggon D, Egger P, Dieppe P. Occupational activity and osteoarthritis of the knee. Ann Rheum Dis 1994;53:90-3.

12 Louyot P, Savin R. La coxarthrose chez l'agriculteur. Rev Rhum 1966;33:625-32.

13 Axmacher $B$, Lindberg $H$. Coxarthrosis in farmers as appearing on colon radiograms and urograms. In: Hogstedt C, Reuterwall C, eds. Progress in occupational epidemiology. Amsterdam: Excerpta Medica, 1988:203-6.

14 Thelin A. Hip joint arthrosis: an occupational disorder among farmers. Am f Ind Med 1990;18:339-43.

15 Vingard E. Work, sports, overweight and osteoarthrosis of the hip. Stockholm: Karolinska Institute, 1991 (dissertation).

16 Vingard E, Hogstedt C, Alfredsson L, Fellenius E, Goldie I, Koster M. Coxarthrosis and physical work load. Scand $\mathcal{f}$ Work Environ Health 1991;17:104-9.

17 Vingard E, Alfredsson L, Goldie I, Hogstedt C. Occupation and osteoarthrosis of the hip and knee: a register-based cohort study. Int f Epidemiol 1991;20:1025-31.

18 Croft P, Cooper C, Wickham C, Coggon D. Osteoarthritis of the hip and occupational activity. Scand $\mathcal{F}$ Work Environ Health 1992;18:59-63.

19 Typpo T. Osteoarthritis of the hip. Acta Chir Gynaecol 1985; 74(suppl 201):1-38.

20 Jacobsson B, Dalen N, Tjornstrand B. Coxarthrosis and labour. Int Orthop 1987;11:311-3.

\title{
Physical activity at leisure and risk of osteoarthritis
}

\author{
Nancy E Lane
}

Exercise, particularly weight bearing sports like running and team sports, remains popular throughout the industrialised world. Evidence supports participating in regular exercise, including recreational activities or competitive sports, as it improves general health and may increase longevity. ${ }^{12}$ Therefore increasing numbers of individuals have chosen to pursue regular exercise programmes. Individuals with normal joints ask whether their exercise programmes increase the risk of developing osteoarthritis, and individuals with osteoarthritis of weight bearing joints ask what types of physical activity might accelerate the progression of their joint disease. Since osteoarthritis is the major cause of activity limitation in the elderly, these questions are relevant public health issues.

In this paper I shall review the studies that address exercise as a risk factor for osteoarthritis in normal and abnormal joints and suggest future studies which may further our understanding of this issue.

\section{Normal joints}

LOW IMPACT

Several studies have examined the relation of jogging to osteoarthritis. ${ }^{3-11}$ While some of the retrospective cross sectional studies show no impact of exercise on osteoarthritis in normal joints ${ }^{3-59}$ others do ${ }^{1011}$.

In 1984, Lane et al initiated a longitudinal study to examine the association of jogging with the development of osteoarthritis and musculoskeletal disability in a group of runners over the age of $\mathbf{5 0}$ years and controls.
Runners were compared with 41 control subjects matched for age, sex, years of education, and occupation. ${ }^{3}$ The results of this initial cross sectional study showed that women runners, at a mean age of 59 years and an average of nine years of running over 200 minutes a week, had more radiographic evidence of knee subchondral sclerosis and osteophytes than controls. However, no increase in self reported knee joint pain or clinical osteoarthritis was found. Male runners were not different in either radiographic or clinical evidence of osteoarthritis from controls. ${ }^{3}$ At the five year follow up, a subgroup of the original cohort was examined. These subjects (mean age 65 years) continued to run 180 minutes per week. ${ }^{7}$ Both runners and controls had significant radiographic progression of the individual radiographic features of osteoarthritis. Five controls and four runners had knee osteoarthritis by the American College of Rheumatology criteria. ${ }^{7}$ Predictors of the radiographic knee osteoarthritis score included age, pace per mile, and weight. ${ }^{7}$ At the nine year follow up, 32 of the original 41 runners and 23 controls were examined (mean age 67 years). In 1993 the radiographic scores for knee osteoarthritis were similar for those still running, those who had stopped running, and those who had never run. ${ }^{12}$

Similar observations were reported by Panush et al. When 17 male runners (mean age 56 years) were compared with age and weight matched controls, ${ }^{4}$ no differences in radiographic or clinical hip, knee, or ankle osteoarthritis were found. An eight year follow up of a subgroup of the original cohort found that both runners and controls had some

\author{
Rheumatology \\ University of \\ Francisco, San \\ Francisco, California \\ 94143, USA \\ N E Lane
}


radiographic progression in joints examined but there were no differences in the radiographic scores between groups. ${ }^{8}$ Thus, these investigators concluded that individuals with normal joints who started jogging in their middle years and continued running did not appear to have accelerated development of osteoarthritis.

Other investigators' results differed for normal joints. Spector et al evaluated life time exercise histories and examined knee radiographs in 977 women from Chingford, England. ${ }^{11}$ Twenty two women reported long term vigorous weight bearing exercise and had a two- to threefold increased risk of radiographic osteoarthritis (particularly osteophytes) of the knee and hip. These investigators concluded that the duration of exercise may increase the risk of osteoarthritis. ${ }^{11}$

\section{HIGH IMPACT AND HIGH INTENSITY}

Other investigators have studied the effect of high intensity and high impact exercise on the development of hip or knee osteoarthritis. Puramen et al compared former Finnish elite distance runners (mean age 56 years) with 21 years of running and found no increased radiographic or clinical osteoarthritis compared to similar aged controls. ${ }^{5}$ Sohn and Micheli performed a retrospective study of former varsity cross country runners and reported that competitive running during former college years did not predispose to knee or hip osteoarthritis. ${ }^{9}$ However, Marti et al found that former national Swiss long distance runners (mean age 27 years) had more radiographic evidence of hip osteoarthritis than bobsled competitors and controls, and that age and mileage run in 1973 were independent predictors of hip osteoarthritis. ${ }^{6}$ Kajula et al performed a retrospective hospital chart review for admissions for osteoarthritis of the hip, knee, and ankle in former Finnish male athletes. $^{10}$ Athletes from all types of competitive sports had a small increase in risk of requiring hospital care for osteoarthritis. Mixed sports (soccer, ice hockey, basketball, track and field) and power sports (boxing, wrestling, weight lifting, throwing) athletes were at higher risk for painful osteoarthritis at a younger age (mean ages 43 and 47 ) than the endurance athletes (mean age 50 years). When life time physical loading histories were examined in a subgroup of 117 former elite athletes, radiographic evidence of knee osteoarthritis was present in $3 \%$ of shooters, $29 \%$ of soccer players, $31 \%$ of weight lifters, and $14 \%$ of runners. ${ }^{13}$ The risk of knee osteoarthritis was increased in subjects with previous knee injuries (odds ratio 4.7), high body mass index at the age of 20 (odds ratio 1.8 /one unit of increasing body weight), previous participation in heavy work (1.08/work year), and in subjects participating in soccer (5.21). These studies conclude that soccer players and weight lifters are at increased risk of knee osteoarthritis. Soccer players' risk may be explained by knee injuries, and weight lifters' by high body mass. ${ }^{13}$

Spector et al studied the risk of osteoarthritis of the hip and knee in ex-elite British long distance runners and tennis players compared to age matched female controls (mean age 52 and 54 years respectively). Both runners and tennis players had a two- to threefold increased risk of radiological osteoarthritis (especially osteophytes) of the knees and hips. The tennis players appeared to have more osteophytes at the tibiofemoral joint and hip, while the runners had more disease of the patellofemoral joint. ${ }^{11}$

Roos et al studied the prevalence of knee osteoarthritis in 71 elite former soccer players, 286 non-elite soccer players, and 582 controls (mean age 55 years) and found it to be $4.2 \%$ in non-elite soccer players, $15.5 \%$ in elite players, and $1.6 \%$ in controls. ${ }^{14}$ When players with documented knee injuries were analysed separately, $13 \%$ of non-elite players had knee osteoarthritis compared to $3 \%$ without injuries. Elite soccer players with no history of knee injury had a knee osteoarthritis prevalence of $11 \%$. ${ }^{15}$ These data suggest that the game of soccer at an elite level is associated with an increased risk for osteoarthritis, in players both with and without injuries. The risk of osteoarthritis has also been reported to be increased in ex-elite football players' knees and baseball pitchers' elbows and shoulders. ${ }^{16-19}$

Thus some evidence suggests that high intensity, high impact professional sports in young adults may be risk factors for the later development of osteoarthritis in joints that have been put under those types of stress.

\section{Abnormal joints}

A moderate amount of weight bearing exercise does not appear to accelerate the development of osteoarthritis in joints of the lower extremity, but weight bearing exercise in subjects who have experienced trauma or have joints with anatomical variances is different. McDermott and Freyne reported that six of 20 long distance runners had radiographic and clinical evidence of knee osteoarthritis. ${ }^{20}$ All six runners had either anatomical variances or a history of knee trauma. Radiographic findings of osteoarthritis were associated with genu varum, a history of previous joint injury, and years of running.

Negret et al studied 77 soccer players $20-30$ years after knee joint injuries and partial meniscectomies. Twenty five per cent of subjects with an intact anterior cruciate ligament had knee osteoarthritis and $71 \%$ of subjects who had ruptured an anterior cruciate ligament had radiographic osteoarthritis. ${ }^{21-23}$ These data further support the theory that osteoarthritis does develop after joint injuries, and injuries to both the meniscus and anterior cruciate ligament appear to accelerate the development of osteoarthritis, both in players who continue to play soccer, and in those who do not .

The delay in time from the joint injury to the development of clinical osteoarthritis in unclear. Boszotto et al evaluated 77 patients two and seven years after partial meniscectomies and at the two year follow up $40 \%$ of the patients had mild to moderate radiographic knee osteoarthritis. Osteoarthritis was correlated with older age of the patients at the time of the procedure. ${ }^{22}$ Negret et al reported that 
individuals less than 35 years of age at the time of knee injury and meniscectomy had a mean delay of 26 years to the onset of osteoarthritis, and those older than 35 years a mean delay of 9.8 years from meniscectomy to the development of clinical osteoarthritis. ${ }^{23}$

\section{Methodological issues}

While the evidence now available allows us to begin to assess the risks of developing osteoarthritis with sporting activities, these studies must still be interpreted with caution for the following reasons. The radiographic methods used to score the radiographs for osteoarthritis and the definitions for osteoarthritis used by the various investigators are not similar. Reliability testing of readers who scored the radiographs by the various methods have not always been performed. Also, most studies on exercise and osteoarthritis are cross sectional. A negative cross sectional study on the development of knee osteoarthritis in runners cannot be interpreted to mean that running does not accelerate osteoarthritis, as subjects must be followed longitudinally to determine whether the disease develops, and whether they stop running because of the development of knee pain and osteoarthritis. In addition, most studies of exercise and osteoarthritis collect retrospective data on joint injuries and exercise histories, and this may lead to inadequate and unreliable data regarding risk factors for the development of osteoarthritis. The development of validated and standardised methods of evaluating the presence and severity of radiographic and clinical osteoarthritis would enable investigators to determine better what types of exercise may be risk factors for the development or progression of osteoarthritis.

\section{Summary}

A summary of the evidence linking exercise and osteoarthritis is given in the table.

In summary, normal joints appear to tolerate prolonged vigorous low impact exercise without accelerated development of osteoarthritis. The risk of developing osteoarthritis appears to be increased in sporting activities that continually expose normal joints to high levels of impact or torsional loading and in individuals who continue sporting activities after they have injured supporting structures in the joint (like ligaments, tendons, and menisci). The hypothesis that high impact loads to joints over time will accelerate the development of osteoarthritis in exposed joints must now be examined in a longitudinal study.

1 Paffenbarger RS, Hyde RT, Wing AL, et al. Physical activity, all-cause mortality, and longevity of college alumni. $N$ Engl f Med 1986;314:605-14.

2 Haskell WL. Exercise and health. In: Wyngarden B, Smith LH, eds. Cecil, Textbook of internal medicine. Philadephia: WB Saunders, 1988:45-8.
Arthritis and exercise: possible associations

\begin{tabular}{|c|c|c|}
\hline Activity & Site & Risk of osteoarthritis \\
\hline $\begin{array}{l}\text { Normal joints } \\
\text { Running } \\
\text { Recreational } \\
\text { Competitive }\end{array}$ & Knee, hip & $\begin{array}{l}\text { Probably not } \\
\text { Possibly increased }\end{array}$ \\
\hline $\begin{array}{l}\text { Soccer } \\
\text { Recreational } \\
\text { Competitive }\end{array}$ & Knee, ankle & $\begin{array}{l}\text { No increase } \\
\text { Possibly increased }\end{array}$ \\
\hline Baseball & $\begin{array}{l}\text { Elbow, } \\
\text { shoulder }\end{array}$ & \\
\hline $\begin{array}{l}\text { Recreational } \\
\text { Competitive }\end{array}$ & & $\begin{array}{l}\text { No increase } \\
\text { Possibly increased }\end{array}$ \\
\hline $\begin{array}{l}\text { Abnormal joints } \\
\text { Running } \\
\text { Soccer } \\
\text { Football }\end{array}$ & $\begin{array}{l}\text { Knee } \\
\text { Knee } \\
\text { Knee }\end{array}$ & $\begin{array}{l}\text { Probably increased } \\
\text { Probably increased } \\
\text { Probably increased }\end{array}$ \\
\hline
\end{tabular}

3 Lane NE, Bloch DA, Jones HH, Fries JF. Running, osteoarthritis and bone density. $\mathscr{F A M A} 1986 ; 255: 1147-51$.

4 Panush RS, Schmidt C, Caldwell JR, Edwards NL, Longley $\mathrm{S}$, Yonker $\mathrm{L}$. Is running associated with degenerative joint disease? ₹AMA 1986;255:1152-5.

5 Puramen J, Ala Ketola L, Peltokullio P, Saarela J, Marshall WH, Wood PJ, et al. Running and osteoarthritis of the hip. BMF 1975;ii:424-5.

6 Marti B, Knobloch M, Tschopp A, Jucker A, Howald H. Is excessive running predictive of degenerative hip disease? Controlled study of former elite athletes. BMF 1989; 299:91-3.

7 Lane NE, Michel B, Bjorkengren A, Oehlert J, Shi H, Bloch $\mathrm{DA}$, et al. The risk of osteoarthritis with running and aging: a 5-year longitudinal study. F Rheumatol 1993; 20:461-8.

8 Panush RS, Hanson CS, Caldwell JR, Longley S, Stork J, Thoburn $R$. Is running asssociated with degenerative joint disease? An eight-year follow-up study. $f$ Clin Rheum disease? An

9 Sohn RS, Micheli LJ. The effect of running on the pathogenesis of osteoarthrtis of the hips and knees. Clin Orthop Rel Res 1985;198:106-9.

10 Kujala UM, Kaprio J, Sarna S. Osteoarthritis of weightbearing joints of lower limbs in former elite male athletes. $B M \mathcal{F}$ 1994;308:231-8.

11 Spector TD, Harris PA, Hart DJ, Cicuttini FM, Nandra D, Etherington J, et al. Risk of osteoarthritis associated with running: a radiological survey of female ex-athletes and population controls. Arthritis Rheum (in press).

12 Lane NE, Bloch DA, Oehlert J, Fries JF.The relationship of running with radiographic osteoarthritis of the knee and lumbar bone mineral density: a 9 year longitudinal study [abstract]. Arthritis Rheum 1995;38:S361.

13 Kujala UM, Kettumen J, Paananen H, Aalto T, Battie MC, Impivarra $\mathrm{O}$, et al. Knee osteoarthritis in former runners, soccer players, weight lifters and shooter. Arthritis Rheum 1995;38:539-46.

14 Roos H, Lindberg H, Gardnell P, Lohmander LS, Wingstrand $H$. The prevalence of gonarthrosis and its relation to meniscectomy in former soccer players. $A m \mathcal{F}$ Sports Med 1994;22:219-22.

15 Lindberg H, Roos H, Gardnell P. Prevalence of coxarthrosis in former soccer players. Acta Orthop Scand 1993;64:165-7. in former soccer players. Acta Orthop Scand 1993;64:165-7.
Rall K, McElroy G, Keats TE. A study of long-term effects of football injury in the knee. Missouri Med 1984;61:435-8.

7 Vincellete $R$, Laurin CA, Levesque HP. The footballer's ankle and foot. Can Med Assoc F 1972;107:873-7.

18 Adams JE. Injury to the throwing arm: a study of traumatic changes in the elbow joints of boy baseball players. California Med 1965;102:127-9.

19 Bennet GE. Shoulder and elbow lesions of the professional baseball pitcher. FAMA 1941;117:510-4.

$20 \mathrm{McD}$ ermott M, Freyne P. Osteoarthritis in runners with McDermott M, Freyne P. Osteoarthritis in

21 Neyret P, Donell ST, DeJour P, Dejour D, Dejour H. Partial meniscectomy and anterior cruciate ligament rupture in soccer players. A study with a minimum 20 -year followup. Am $\mathcal{F}$ Sports Med 1993;21:455-60.

22 Boszotto $H$, Helperstorfer $W$, Kolndorder G. Long-term results of arthroscopic meniscectomy. Aktuelle Traumatol 1994;24:30-4.

23 Negret P, Donell ST, Dejour H. Osteoarthritis of the knee following meniscectomy. $\mathrm{Br} \mathcal{F}$ Rheumatol 1994;33:267-8. 